\title{
4. EL PRINCIPIO POLITICO FORMAL DE IDENTIDAD EN EL ORDENAMIENTO CONSTITUCIONAL ESPAÑOL
}

\author{
ALBERTO OLIET PALA
}

Universidad Autónoma de Madrid 


\section{SUMARIO}

SEGUNDA PARTE.-A.-LA INCIDENCIA DEL PRINCIPIO DE IDENTIDAD EN EL ORDENAMIENTO CONSTITUCIONAL ESPAÑOL. I.-LAS MANIFESTACIONES DE IDENTIDAD DEMOCRATICA EN LA CONS. TITUCION. EL DERECHO A PARTICIPAR DIRECTAMENTE EN LOS ASUNTOS PÚBLICOS. II.-EL DERECHO DE PETICION. III.-LA INICIATIVA LEGISLATIVA POPULAR. IV.-EL REFERENDUM. 1. El referéndum consultivo. 2. Los referendos autonómicos. 3 . El referéndum para la reforma constitucional. 4. Facultades concedidas a los partidos en la convocatoria de referendos. V.-La JUSTICIA POPULAR Y EL CONCEJO ABIERTO. VI.-LA RESTRICCIÓN DEL PRINCIPIO DE IDENTIDAD. VIII.-LA INTERPRETACIÓN EXTENSIVA DEL PRINCIPIO REPRESENTATIVO.

B.-LA PROBLEMÁTICA DE LAS CONSTITUYENTES. EL RECHAZO A LA DEMOCRACIA DE IDENTIDAD. I.-LA POSICION DE LOS GRUPOS POLITICOS. II.-CONSERVADURISMO Y DEFENSA DE LA DEMOCRACIA DE IDENTIDAD. III.-EL CONSENSO Y LA OPCIÓN DE LOS CONSTITUYENTES POR UNA DEMOCRACIA ESTRICTAMENTE REPRESENTATIVA. 
Revista de Derecho Político, núm. 24, 1987, pp. 87-123

\section{EL PRINCIPIO POLITICO FORMAL DE IDENTIDAD EN EL ORDENAMIENTO CONSTITUCIONAL ESPAÑOL}

POR

ALBERTO OLIET PALA

Universidad Autónoma de Madrid

SEGUNDA PARTE

\section{A. LA INCIDENCIA DEL PRINCIPIO DE IDENTIDAD EN EL ORDENAMIENTO CONSTITUCIONAL ESPAÑOL}

\section{LAS MANIFESTACIONES DE IDENTIDAD DEMOCRATICA EN LA CONSTITUCION}

La Constitución española de 1978 es formalmente mixta en este aspecto, en la medida en que ambos principios están presentes y declarados en el texto. Es claro, por supuesto, que, como en todas las actuales democracias, el dominante es el representativo. Lo que, esencialmente, analizaremos es la aparición y relevancia de las instituciones en donde se manifiesta o predomina la identidad en contraste con el principio de representación.

Estudiaremos la competencia que la puesta en funcionamiento de los mecanismos de democracia directa hace a la representación política.

Posibles concreciones del principio de identidad en el texto constitucional son: la participación directa de los ciudadanos en los asuntos públicos del artículo 23, el derecho de petición del 29, la iniciativa legislativa popular del 87, los diversos tipos de referéndum, la justicia popular abordada en el artículo 125, y la referencia al concejo abierto y a la participación del pueblo no representado en la reforma constitucional.

El derecho de los ciudadanos «a participar directamente o por me- 
dio de representantes" ocupa su lugar en la parte dogmática (Capitulo segundo, sección $1 .^{a}$ de los derechos fundamentales y de las libertades públicas), sin que, al parecer, planteara ningún conflicto de importancia en el debate constituyente ${ }^{1}$, pues llegó al texto actual sin ningún cambio. Su inserción en la parte «noble» del texto, la declaración de derechos, no demasiado usual en el derecho comparado ${ }^{2}$, muestra en principio el deseo de los constituyentes de remarcar la institucionalización de la democracia de identidad.

\section{EL DERECHO DE PETICION}

El derecho de petición tiene en nuestro texto constitucional una doble ubicación. La declaración de derechos -artículo 29- lo recoge: "Todos los españoles tendrán el derecho de petición individual y colectiva, por escrito, en la forma y con los efectos que determine la ley". EI Título III, “De las Cortes Generales", lo desarrolla parcialmente (art. 77, 1 y 2): 1. "Las Cámaras pueden recibir peticiones individuales y colectivas, siempre por escrito, quedando prohibida la presentación directa por manifestaciones ciudadanas. 2. Las Cámaras pueden remitir al Gobierno las peticiones que reciban. El Gobierno está obligado a explicarse sobre su contenido, siempre que las Cámaras lo exijan". El postergado desarrollo de este derecho fue realizando sólo parcialmente por el Reglamento del Senado ${ }^{3}$ que crea una comisión encargada de la admisión y tramitación de las peticiones y lo vuelve a remitir a la ley futura.

Lo más destacable es que el ejercicio de este derecho no hace preceptivo el pronunciamiento público del órgano legislativo sobre el contenido de la petición. Sólo se obliga a ello al Gobierno si las Cortes así lo exigen ${ }^{4}$.

Del debate constituyente en torno al derecho de petición ${ }^{5}$, que no

1 Carro Martinez, de Alianza Popular, propuso una enmienda a ese apartado: "Todos los ciudadanos mayores de edad tienen derecho de surragio activo y pasivo en la forma determinada en las leyes". FERNANDEZ DE LA MORA, propuso la supresión del apartado.

2 La Ley Fundamental de la República Federal alemana no incluye en su parte dogmática ninguna referencia a ella. La Constitución francesa en el Título I, "La Soberania" y en su artículo $3^{\circ}$, señala que ésta "pertenece al pueblo que la ejerce a través de sus representantes y por vía de referéndum. La Constitución italiana especifica en su declaración de derechos (art. 49), el de los ciudadanos o "asociarse libremente en partidos políticos para concurrir con método democrático a determinar la política nacional".

3 De 26 de mayo de 1982. BOC - Senado-, Sección III, núm. 13, de 4 de junio de 1982. Título XX, "De las peticiones".

4 En el Reglamento del Senado se indica que entre los acuerdos posibles de la comisión está el archivarios sin más trámite. (Apartado $4 .^{\circ}$ del art. 193).

5 En relación con este debate, ver el artículo de MAnUel Ramirez, "Democracia directa y constitución: problemática y desarrollo legislativo". En El desarrollo de la Constitución española de 1978, (varios autores). Libros Pórtico. Zaragoza, 1983. 
tuvo incidencias en lo que se refiere al artículo 29 , es destacable el hecho de que de haberse mantenido el voto particular de Alianza Popular en su totalidad, el artículo 77 contaría con dos apartados más referidos sustancialmente a la posibilidad de que "grupos legítimos de interés", fueran recibidos en las comisiones parlamentarias, en sesiones públicas ${ }^{6}$.

\section{LA INICIATIVA LEGISLATIVA POPULAR}

La iniciativa legislativa popular se incorporó al constitucionalismo europeo a finales de la primera guerra mundial ${ }^{7}$. A pesar de esa veteranía, no se ha llegado todavía a generalizar la concesión de la potestad para iniciar el procedimiento de formación de la ley a una fracción del cuerpo electoral. La Constitución francesa, relativamente reciente, no la menciona y la Ley Fundamental de Bonn, por ejemplo, sólo contempla una especie de iniciativa popular, no propiamente legislativa, cuyo objeto es la reorganización territorial de los Länders ${ }^{8}$. En el constitucionalismo socialista hace su aparición esta institución, pero condicionada por las peculiaridades de la organización del poder en los mismos ${ }^{9}$. Sin embargo, la amplitud con que ha sido acogida la iniciativa en el ordenamiento italiano ${ }^{10}$ y suizo ${ }^{11}$ ha tenido una significativa incidencia en el funcionamiento del sistema político en estas democracias.

6 La redacción del artículo 77 recoge el voto particular de Alianza Popular en sus dos primeros apartados, quedando los otros dos rechazados ya en la Comisión de Asuntos Constitucionales del Congreso.

7 Ya contemplaban esta institución la Constitución del Reich Alemán de 11 de agosto de 1919 (art. 73); la de la República de Baviera de 14 de agosto de 1919 (art. 10); la de Austria de 1 de octubre de 1920 (art. 41); la de la República de Prusia de 30 de noviembre de 1920 (art. 6); la del Estado Libre de Irlanda de 5 de diciembre de 1922 (art. 48).

8 Artículo 29, número 2 de la Ley Fundamental de Bonn:

9 La Constitución de la República Popular de Bulgaria de 18 de mayo de 1971 -artículo 80 - estipula que el derecho de iniciativa de las leyes corresponde a las organizaciones sociales, de las que enumera una lista. La Constitución de la República Democrática Alemana (6 de abril de 1968, art. 65) concede ese derecho a las "organizaciones de masas". La de la URSS (7 de octubre de 1977) lo hace a las "organizaciones sociales representadas por sus organismos a escala federal» (art. 113). La Constitución cubana (29 de febrero de 1976), sin embargo, regula un tipo de iniciativa análoga a las de las democracias liberales: el artículo 86 indica que la iniciativa de las leyes compete ca los ciudadanos. En este caso será requisito indispensable que ejerciten la iniciativa diez mil ciudadanos, por lo menos, que tengan la condición de electores".

${ }_{10}$ Sobre la iniciativa legislativa popular en Italia cabe destacar las siguientes obras: Cerutti, Le norme del referendum e delliniziativa legislativa populare. N. Grass. Idg., 1949; H. BATTELLI, "La instituzioni di democrazia diretta", en Comentario sistematico alla Constituzioni. Florencia, 1950. Volumen II, págs. 76 y sig.; R. PADIRAC, "Les institutions de Democratie directe en Italie", en Revue Internationale de Droit Comparée, Juillet, 1972; F. Cuocolo, «Iniziativa legislativa", en Enciclopedia del Diritto, tomo XXI, Giuffre, Milán, 1971; GALEOTTI, Contributo alla teoría del procedimiento legislativo, Giuffre, Milán, 1957, págs. 244 y sig.; G. LuCıFREDI, L'iniziativa legislativa parlamentare, Giuffre, Milán, 1968.

11 Sobre la iniciativa legislativa popular en Suiza: J. MEYNAUD, La democratie semidi- 
Nuestros diputados constituyentes del 78 , y siguiendo el criterio de sus antecesores de la Segunda República ${ }^{12}$, dieron cabida a la iniciativa popular, aunque el propósito explicitado en el Anteproyecto constitucional quedó sustancialmente recortado en la regulación vigente.

El artículo 87.3 de nuestra norma fundamental exige no menos de 500.000 firmas para la presentación de la iniciativa popular y excluye de la misma a las normas tributarias, a las de carácter internacional, a la prerrogativa de gracia y a las materias propias de ley orgánica. Esta última restricción, que fue impuesta en la Comisión Mixta Congreso-Senado, es de mucho alcance, puesto que, según el artículo 81 del mismo texto, serian "leyes orgánicas las relativas al desarrollo de los derechos fundamentales y de las libertades públicas, las que aprueben los Estatutos de Autonomía y el régimen electoral general y las demás previstas en la Constitución» ${ }^{13}$.

Otra limitación material a la que se refiere el texto es la reforma constitucional, que el artículo 166 excluye de la iniciativa popular: éste preceptúa que la iniciativa de la misma se ejercerá en los términos previstos en los apartados 1 y 2 del artículo 87, sin mencionar un apartado tercero referido a la iniciativa legislativa popular.

Antes de la promulgación de la Ley Orgánica a la que la norma de referencia encomendaba la regulación de las formas de su ejercicio y los requisitos de la misma, la institución fue parcialmente reglada en cumplimiento del artículo 89.1, que encomendaba el desarrollo normativo de la tramitación de las proposiciones de ley a los Reglamentos de las Cámaras. Así lo hace el del Congreso de los Diputados de 10 de febrero de 1982 en sus artículos 126 y 127. Lo más destacable fue la creación de un llamado "trámite de toma en consideración» ${ }^{14}$, según el cual, las Cámaras se reservaban el derecho a aceptar o denegar la entrada del proyecto en la publicidad de la discusión parlamentaria.

recte en Suisse, Montreal, 1970, Volumen I, págs. 13 y sig.; Dusan SIDJANSKL, ChaRLES RoIG y HenrI Kerr, Les Suisses et la politique, Berne, H. Lang 1975; J. C. LAMBELEC, «Decisions collectives et democratie reférendaire en Suisse», Rapport 2-3 octubre, 1977, págs. 17 a 26. 12 El párrafo 3 del articulo 66 de la Constitución de 1931 concedía el derecho de iniciativa al pueblo «siempre que lo pida, por lo menos, el 15 por 100 de los electores».

13 La Constitución es prolija en sus remisiones a la regulación por Ley orgánica: así, el artículo 107 lo hace con la composición y competencias del Consejo de Estado; el artículo 15 con la institución del Defensor del Pueblo; el 104.2 con las funciones y principios básicos de actuación y estatutos de las Fuerzas y Cuerpos de seguridad; el 122.1 con la organización del Poder Judicial, el 8.2 con las bases de la organización militar; el 161 con la organización, funciones, etc. del Tribunal Constitucional; el 1364 con la composición, organización y funciones del Tribunal de Cuentas.

14 Sobre este trámite en el Reglamento del Congreso, ver el artículo de RAMÓN PUN. SET, “Iniciativas popular y regional y fase introductoria del procedimiento legislativo". En $R E P$, n. $^{\circ} 22$, julio y agosto, 1981 , págs. 215 y ss. 
La Ley Orgánica reguladora de la iniciativa legislativa popular ${ }^{15}$, contempla un "examen de admisibilidad", que corre a cargo de la Mesa del Congreso (art. $4 .{ }^{\circ}$ ), y establece unos criterios para juzgar la admisión o no de la proposición (art. $5^{\circ}$ ), que debe ser presentada por una "Comisión Promotora" con anterioridad a la recogida de firmas.

De esta Ley hay que destacar también que se inclina por la iniciativa formulada al estilo italiano, pues exige que el presentado ante la Comisión sea un texto articulado dotado de unidad "sustantiva" ${ }^{16}$.

Por otro lado, la Ley Orgánica añade en su artículo segundo nuevas materias a las excluidas de la iniciativa popular por el artículo 87.3. En concreto, se refiere a las mencionadas en los artículos 131 y 134.1 de la norma fundamental, que reservan a un órgano del Estado - concretamente al Gobierno- la iniciativa para la elaboración de los proyectos de planificación económica general y para la de los Presupuestos Generales del Estado.

Como observación general cabe decir que la admisión de la iniciativa legislativa en nuestro ordenamiento es una favorable concesión a la democracia de identidad prometida en el artículo 23.1. No obstante, en la regulación de la misma han prevalecido criterios restrictivos, que ponen de manifiesto la orientación del legislador constituyente hacia el parlamentarismo, entendido en sentido estricto, y que han detraído a la institución gran parte de sus virtualidades.

Si de lo que se trata es de instrumentar la directa participación del titular de la soberanía en la elaboración de normas, ampliando la que tan escuetamente se realiza a través del acto electoral, no se explica ese amplísimo marco de excepciones. En la legislación italiana - tanto en el artículo 71 , en el que se regula la institución, como en la Ley de 25 de mayo de 1970, referente a las normas sobre el referéndum e iniciativa legislativa popular, previstas en la Constitución- no aparece ninguna materia vetada a la iniciativa popular, ni siquiera en lo que respecta a la revisión constitucional. En el ordenamiento suizo (Constitución Federal de la

15 BOCG -Congreso-. Serie A, 48-I, de 4 de julio de 1983.

16 La iniciativa legislativa popular se distingue (PAOLO BISCARETTI DI RUfFIA, Derecho constitucional, Tecnos, Madrid, 1973) en simple, cuando se concreta en una moción encaminada a que aprueban las Cámaras una ley con un contenido específico, y formulada, cuando el proyecto de ley debe ser elaborado por los mismos que lo presentan. En el ordenamiento suizo (art. 1211, número 4) se permiten las dos, pues se establece que, "La petición de la iniciativa puede revestir la forma de una proposición concedida en términos generales o la de un proyecto redactado en todas sus partes". La Constitución italiana exige un proyecto redactado en artículos (art. 71). El anteproyecto de la ponencia constitucional, punto de partida de nuestra Constitución del 78 se pronunciaba por la exigencia de un texto articulado y motivado, aunque esto desaparece ya en el texto aprobado por la Comisión Constitucional del Congreso. 
Confederación suiza de 29 de mayo de 1874 y Ley federal sobre derechos políticos, de 17 de diciembre de 1976), la iniciativa legislativa popular se reserva para la reforma constitucional. No parece que la práctica de estas fórmulas de democracia semi-directa en estos paises haya servido "de fácil cauce para las manipulaciones demagógicas, o incluso para legitimar con un supuesto consenso, lo que no es en sustancia sino la antidemocrática imposición de la voluntad de una minoría", que son las razones que da el legislador en la exposición de motivos del proyecto de ley orgánica para excluirla "de campos normativos particulares delicados".

El requisito de las 500.000 suscripciones es también expresión de los recelos con los que se legisla sobre la iniciativa popular. Es cierto que es el único antecedente que obra en nuestra historia, la Constitución de 1931, las prevenciones eran aún mayores, pues se exigía el apoyo para la iniciativa del 15 por 100 del electorado. También el que en Suiza, por una votación popular celebrada en el año 1971, se duplicó el número de suscripciones para la iniciativa, que quedó en 100.000 electores, aunque no hay que olvidar que esta iniciativa se refiere a la revisión constitucional. Pero el ejemplo de la Constitución italiana, que concede al pueblo el ejercicio de la iniciativa popular mediante la proposición de sólo 50.000 electores, también podía haber servido de referencia a nuestros constituyentes.

Aunque con el número de firmas exigidas se pueda fundamentar en el razonable criterio de evitar una proliferación excesiva de la iniciativa popular, aquel requisito tiene otras consecuencias de importancia: contribuye a diluir el sentido genuino de la institución. Si se la adjetiva de "popular" es precisamente para reseñar que una facultad que por su naturaleza sería competencia del poder legislativo o del ejecutivo, se encomienda a una parte no organizada del cuerpo electoral. «Lo específico del concepto "pueblo" - insito en la idea de iniciativa popular- consiste en que éste es una entidad no organizada y nunca organizable por completo", escribe CARL SCHMITT ${ }^{17}$. Se entiende que una masa de ciudadanos, no mediada por los canales institucionales habituales, es la que debe suscitar la iniciativa. Cuanto más inorgánico sea el grupo que la pone en marcha, más se cumplirá con el sentido original de institución. Por ello, a mayor exigencia numérica, menores posibilidades de que esto se realice al margen de las organizaciones políticas asentadas y que dominan la articulación de la decisión política en el sistema. Si un partido con una cantidad suficiente de afiliados y simpatizantes suscita permanentemente iniciativas populares, se deformaría el sentido de esta institución: se trataría de acciones políticas de partido. Lo que de identidad democrática tiene esta iniciativa, es decir, dar entrada en la función legis-

17 Schmiт, Teoría de la constitución, pág. 280. 
lativa a movimientos de opinión surgidos «espontáneamente» —o por lo menos no «formados" por las organizaciones institucionales - frente al rigido mecanismo de la representación política en la formación de la ley, se pierde con la intervención de los partidos ${ }^{18}$.

Desde otra perspectiva, una aportación subsidiaria de la iniciativa popular a la democracia de identidad, pero potencialmente eficaz, es la que deriva de la publicidad que puede incorporar a los mecanismos de decisión política, tan solapados en el complejo entramado de intereses que juegan en las actuales democracias de masas. Aunque la decisión final está en el Parlamento, la iniciativa puede coadyuvar a la publicitación de su actividad.

Al margen de la expectación que sobre la futura decisión parlamentaria genere por su reflejo en los mass media, la iniciativa popular $-y$ esto es lo relevante- puede compeler a la toma de determinadas decisiones político-parlamentarias, marginadas o suspendidas por concertaciones no públicas que tienden a garantizar, por ejemplo, determinados intereses de grupos económicos o de aparato del Estado, ante los que se pliegan las fracciones parlamentarias. Es decir, provocaría la toma de postura del Parlamento, de sus mayorias, sobre determinados asuntos, y contribuiría a dar publicidad de las presiones sociales extraparlamentarias y a explicitar las ocultas ataduras de todo sistema democrático. Por ello, la organización de iniciativas, no mediatizada por partidos parlamentarios, serviria mejor a la intención que subyace a la institución.

Sin duda, la iniciativa popular puede aportar al Parlamento la publicidad que le da sentido, forzando, por lo menos, a que determinados compromisos no se excluyan de la misma.

En este contexto, el mencionado trámite de "toma en consideración", previsto en el Reglamento del Congreso y regulado en la Ley, puede permitir, en la práctica, que el propio Parlamento vote a priori la discusión en su seno de determinadas, iniciativas, lo que restaria, por lo menos, "notoriedad» pública al tema que con aquéllas se quisiera sacar a la luz ${ }^{19}$. La iniciativa popular no pone en marcha con carácter vinculante el procedimiento legislativo, sino que está sujeta a un trámite previo

18 En la exposición de motivos del proyecto de Ley Orgánica significativamente se alude a que el ejercicio de la iniciativa se regula "en forma tal que, respetando al máximo el papel institucional de los partidos políticos como órganos de manifestación de la voluntad popular e instrumentos fundamentales de la participación política, se canalice el ejercicio de la iniciativa con las máximas garantias".

19 Santamaría Pastor (En F. Garrido Falla y otros autores, Comentarios a la Constitución, Civitas, Madrid, págs. 884 y ss.) comentando el Reglamento del Congreso en relación con la norma fundamental, indica que "la iniciativa es un acto de voluntad cuyo único efecto es el de poner en marcha vinculantemente para las Cortes el procedimiento legislativo", por lo que debe darse su admisibilidad automática, sin necesidad de la toma en consideración por el Congreso de los Diputados, consolidándose con la mera reunión de firmas y la presentación del texto correspondiente. 
de admisión a la propia publicidad parlamentaria. Esto no es, probablemente, importante desde el punto de vista de los resultados de la labor legislativa, sujetos en cualquier caso al juego de las mayorias parlamentarias, reproducidas en la Mesa del Congreso que decide sobre la admisión o no del proyecto para su debate en el mismo. Pero es una traba a la virtualidad de la institución en el terreno de la publicitación de la política.

Hay que decir, no obstante, en beneficio del proyecto de ley, que la inclusión de los criterios de inadmisión de la propuesta por el artículo quinto del mismo y el establecimiento por el sexto de un recurso de amparo contra la decisión del Congreso de no admitir la proposición de ley, resta la discrecionalidad que a aquélla otorgaba el artículo 120 del Reglamento del Congreso.

No se puede olvidar la importante aportación de la práctica de la iniciativa popular en la intensificación de los elementos democráticos de los actuales sistemas constitucionales. La desvinculación popular del proceso de formación de la ley, derivada de la supresión de todo mandato imperativo, y motivada por imperiosas exigencias de eficacia técnico-política, no justifica , análogamente, la restricción de la iniciativa popular, sino, por el contrario, hace más necesario el que se posibilite -como advierte KELSEN - que «en el seno del pueblo se manifiesten inspiraciones a las cuales ajuste el Parlamento su actividad legislativa» ${ }^{20}$.

\section{EL REFERENDUM}

Nos referiremos ahora al referéndum. No se trata de hacer un análisis pormenorizado de su régimen jurídico en nuestro sistema, cosa, por los demás, ya realizada con cierta exhaustividad ${ }^{21}$ sino, más bien, en la tónica de nuestro estudio, examinar las posibilidades que a la democracia de identidad concede el marco normativo de la ordenación constitucional del referéndum.

Como es sabido, se contemplan tres tipos de referendos ${ }^{22}$ : el del

20 Hans Kelsen, Esencia y valor de la Democracia, pág. 66.

21 A modo de ejemplo cabe citar el trabajo de EnRIQUE Linde Paniagua y Miguel HERRERo LERA, "El referéndum en la Constitución española de 1978", Boletín informativo del Departamento de Derecho Político de la UNED, número 3, primavera 1979. Referido a un tipo específico, el referéndum consultivo, es de destacar el artículo de PEDRo CRUz VILLALON, «El referéndum consultivo como modelo de racionalización constitucional", en Revista de Estudios Políticos, enero-febrero de 1980. El estudio, ya citado, de Manuel Ramírez ("Democracia directa y Constitución; problemática y desarrollo legislativo") incorpora la normativa que desarrolla nuestro texto constitucional.

22 Conviene destacar que en nuestra Constitución se hace uso del término referéndum en su sentido más amplio, es decir, incluyendo las manifestaciones directas del cuerpo 
art. 92 de la Constitución, conocido como referendum consultivo, el autonómico de los artículos 151 y 152 y de la disposición transitoria cuarta, y el de la reforma constitucional sobre el que versan los artículo 167.3 y 168. La Ley Orgánica sobre la Regulación de las distintas modalidades de Referéndum de 18 de enero del 80 , completa el régimen jurídico de los distintos tipos referenciados.

En orden a su fundamento jurídico en nuestra Constitución, el referéndum puede ser obligatorio, es decir, impuesto necesariamente por la misma como trámite previo a la realización de un acto jurídico-político determinado. Tal es el caso del autonómico de los artículos 151 y 152 de la Constitución, desarrollado en los artículo 8 y 9 de la Ley Orgánica; o del establecido en la disposición transitoria cuarta de aquélla, para el caso específico de la incorporación de Navarra al régimen autonómico vasco; y de la ratificación de la reforma constitucional del 168. También se observa por nuestra normativa el referéndum facultativo, es decir aquel cuya realización no es preceptiva sino determinada por la voluntad de una instancia estatal: es el caso del referéndum consultivo del artículo 92 y del previsto para la reforma constitucional en el artículo 167,3.

\section{El Referéndum consultivo}

Dicho esto con carácter general, nos referiremos, primero, a la consulta popular directa establecida en el artículo 92, que articula el procedimiento de democracia semi-directa de más peso en nuestro sistema político. Dicho artículo dice: «1. Las decisiones políticas de especial trascendencia podrán ser sometidas a referéndum consultivo de todos los ciudadanos; 2. El referéndum será convocado por el Rey, mediante propuesta del Presidente del Gobierno, previamente autorizada por el Congreso de los Diputados". El articulo 6 de la Ley Orgánica añade a esto que la autorización del Congreso deberá realizarse por mayoría absoluta.

El texto de la ponencia, usado como punto de partida para el posterior debate en la Asamblea de Asuntos Constitucionales y en los plenos del Congreso y el Senado, era mucho más ambicioso en términos de democracia de identidad que el aprobado finalmente: admitía la posibilidad

electoral tanto respecto a un acto normativo como a aquellas otras referidas a la manifestación no actuada en relación con un acto de ese tipo, sino más bien, respecto a un simple hecho o suceso concerniente a la estructura esencial del Estado o de su Gobierno. En este último caso es más exacto hablar de plebiscito. De hecho, en una sola ocasión la Constitución usa ese término en ese sentido: la disposición adicional segunda se refiere a «los territorios que en el pasado hubieran plebiscitado afirmativamente proyectos de Estatuto de Autonomía". 
de que fueran sometidas a referéndum la aprobación de leyes votadas en Cortes y aún no sancionadas y la derogación de leyes en vigor, preveía la iniciativa popular para la convocatoria del mismo; no exigia la autorización del Congreso de los Diputados para su celebración, y le atribuía un carácter impositivo frente al meramente consultivo que le da la norma vigente ${ }^{23}$.

En lo que se refiere al referéndum legislativo con eficacia abrogativa, la actitud negativa de los grupos políticos se fue radicalizando en las sucesivas fases del debate. Ya a la Comisión de Asuntos Constitucionales del Congreso llegó reducido en su campo de acción; se había excluido del mismo a las leyes orgánicas en el informe previo de la ponencia constitucional que recogió un voto particular del grupo socialista ${ }^{24}$. En aquella Comisión, y por enmienda in voce del diputado Solé Tura, que modificó la totalidad del artículo, se suprime absolutamente el referéndum abrogativo, quedando reducido su contenido a las decisiones políticas de especial trascendencia ${ }^{25}$.

En la supresión del referéndum legislativo está presente un precavido criterio exclusivista en favor de las Cortes Generales, a las que se concede el monopolio en la aprobación, derogación y modificación de las leyes. Con ella se quiso evitar también el peligro que para una mayoría parlamentaria podia suponer la no ratificación por consulta popular directa de una ley votada favorablemente pero todavía no sancionada, a la derogación de una aprobada en la legislatura con la consiguiente desconfianza que, sobre el mantenimiento de su preeminencia electoral, ello provocaría. Esto hubiera sido un supuesto muy probable, ya que, en el anteproyecto (en lo que respecta a la derogación de leyes), se admitía la iniciativa popular.

El principio político-formal de la representación salió considerablemente reforzado con este cambio: se erradicaron previsibles "mociones populares de censura" al Parlamento y se vetó a la democracia de identidad en la producción de la ley. El especial énfasis de nuestros constituyentes por preservar aquel principio se pone de manifiesto si obser-

23 Artículo 85 del Anteproyecto de Constitución (BOC de 5 de enero de 1978) elaborado por la Ponencia.

24 Enmienda 416: «La aprobación de leyes aprobadas por las Cortes y aun no sancionadas o de decisiones políticas de especial trascendencia y la derogación de leyes en vigor, podrán ser sometidas a referéndum de los ciudadanos".

25 Sesión del 10 de junio de 1978 de la Comisión de Asuntos Constitucionales. Según ha escrito uno de los protagonistas de aquel debate, OsCAR ALZAGA, aquella enmienda de SOLE fue producto del consenso entre todos los grupos presentes en la Comisión, en el que no se integró AP (OSCAR ALZAGA, Comentario sistemático a la constitución española de 1978. Madrid, 1978, pág. 581). Paradójicamente, un diputado de la misma formación que Solé. Tomás García Garcia, había presentado a su vez una enmienda (703) que reducía el referéndum a la derogación de las leyes vigentes y excluía del mismo a las decisiones de especial trascendencia. 
vamos que no sólo la Constitución suiza -ejemplo de institucionalización de la democracia directa- contempla este tipo de referéndum, sino que lo hacen también, y sin remilgos, la italiana y la española de $1931^{26}$. Por otro lado, el riesgo de plebiscitarismo, usado como contraargumento, está tan presente o más en «la apelación al pueblo» para una decisión de especial trascendencia.

Entre las modificaciones recogidas por el texto definitivo hay que incluir la del carácter "consultivo» del referéndum: en el apartado 4 del anteproyecto de la ponencia constitucional se establecia que su resultado se imponía a los ciudadanos y los órganos del Estado. La referida enmienda de Solé Tura suprimió ese apartado 4 y fijó su carácter consultivo, con lo que se dejó en manos del ejecutivo la decisión sobre la aplicación o no de los resultados de la consulta popular.

Otra de las innovaciones - de alguna forma también restrictiva de las potencialidades del referéndum como mecanismo de democracia semi-directa-incorporada al texto final, fue el requisito de la autorización del Congreso para la convocatoria del mismo. En el proyecto inicial de la ponencia constitucional se conferia a las Cámaras la capacidad de iniciar el procedimiento que diera lugar a la consulta directa al cuerpo electoral, pero no la de autorizar necesariamente por mayoría absoluta cualquier convocatoria, tal como establece el artículo sexto de la Ley Orgánica, que desarrolla el artículo 92.2 de la Constitución.

En el texto dictaminado por la Comisión de Asuntos Constitucionales y Libertades Públicas se exigía ya el «previo debate del Congreso de los Diputados» 27 , lo que permaneció inalterado hasta que en el pleno constituyente del Senado se dictamina la necesidad de la «previa autorización del Congreso de los Diputados" 28.

Lógicamente la preceptiva autorización del Congreso de los Diputados tiene el sentido de hacer posible el veto de cualquier convocatoria directa que pueda poner en entredicho la buena aplicación del mandato representativo. El Parlamento siempre podrá excluir con ello la eventualidad de una colisión entre los dos principios de legitimidad, el de representación y el de identidad, en perjuicio de éste.

Lo dicho, de todas formas, hay que valorarlo atendiendo a lo que

26 La Constitución italiana en su artículo 75, lo consagra al establecer que el Presidente de la República puede convocar referendos para la abrogación total o parcial de una ley o de un acto que tenga valor de ley en determinados supuestos. El artículo 66 de la Constitución de nuestra segunda república indica que «el pueblo podrá atraer a su decisión mediante referéndum las leyes votadas por las Cortes. Bastará, para ello, que lo solicite el 15 por 100 del Cuerpo electoralm.

27 Asílo estableció el artículo 86 del Anteproyecto de Constitución (BOC de 1 de julio de 1978), dictaminado por la citada Comision.

28 El texto definitivo fue en realidad producto de la modificación de estilo realizada en la Comisión Mixta del Congreso y el Senadó (BOC de 28 de octubre de 1978). 
es la cuestión primera y básica: ¿Quién detenta la facultad de provocar el referéndum? Esta corresponde en nuestra Constitución al Presidente del Gobierno, que lo propone al Rey; si, como en el caso español, el Gobierno se forma de acuerdo con las mayorias parlamentarias, se puede considerar como una reiteración la exigencia de autorización por las Cortes. El partido o la coalición mayoritaria en el poder será quien en la práctica provoque su convocatoria: sólo la mayoría absoluta, exigida por el artículo 6 de la Ley Orgánica para la citada autorización, podría dar pie a un veto del órgano legislativo al referéndum planteado por un Gobierno con un precario apoyo parlamentario.

Lo esencial es que la regulación constitucional del referéndum del artículo 92 concede al órgano colegiado de representación, y al Gobierno por éste designado, el monopolio en su convocatoria, cuando un aspecto esencial, desde el punto de vista de la democracia de identidad, en la consulta popular directa, es la posibilidad de discutir la voluntad estatal canalizada a través del mecanismo representativo. Se trata con ella, cuando menos, de sacar del ámbito parlamentario una determinada decisión política, de dar al cuerpo electoral una participación añadida, al margen de sus representantes. Por otro lado, esta tutela gubernamental-parlamentaria realza una potencialidad negativa de la institución: su posible instrumentación refrendataria.

En otros ordenamientos constitucionales se contempla el supuesto de que un órgano no dependiente políticamente del Parlamento pueda instar la realización del referéndum. Es el caso del Presidente en la Constitución francesa de 1958, dotado de legitimidad electoral propia, y que puede convocarlo a instancia de su Gobierno ${ }^{29}$.

Aquí la consulta popular puede ser de utilidad en la resolución de conflictos entre los poderes ejecutivo y legislativo. Pero esta posible función de arbitraje hay que entenderla como ejercida también en el ámbito de la tutela de un órgano de representación, en este caso unipersonal: el Presidente.

Otra posibilidad es que se faculte en este sentido a determinados entes territoriales como hace la Constitución italiana, en la que cinco Consejos regionales pueden requerir la realización del referéndum al Presidente de la República ${ }^{30}$. El Anteproyecto elaborado por la ponencia constitucional, punto de partida de nuestro proceso constituyente, en su

29 El artículo 11 de la vigente Constitución francesa establece que «EI Presidente de la República, a propuesta del Gobierno durante los períodos de sesiones o a propuesta conjunta de las dos Asambleas publicadas en el Diario Oficial, puede someter a referéndum cualquier proyecto de ley que se refiera a la organización de los poderes públicos, que entrañe la aprobación de un acuerdo de comunidad o que tienda a autorizar la ratificación de un tratado, que, sin ser contrario a la Constitución, pudiera afectar al funcionamiento de las instituciones".

30 Artículos 75 y 132 de la Constitución italiana de 22 de diciembre de 1947. 
artículo 80 preveía su convocatoria a partir de la iniciativa de tres Asambleas de Territorios Autónomos ${ }^{31}$.

Sin embargo, lo que de verdad impulsaría las potencialidades de esta institución sería la admisión de la iniciativa popular, no contemplada en nuestra normativa constitucional. La iniciativa concedida a 750.000 electores para promover referendos, que afectaran exclusivamente a la derogación de leyes en vigor, prevista por la Ponencia constitucional, fue finalmente rechazada en la Comisión de Asuntos Constitucionales ${ }^{32}$.

La iniciativa popular en la convocatoria del referéndum se perfila como la pieza clave para la institucionalización de la democracia de identidad. Aceptada por la Constitución italiana ${ }^{33}$ y, como no, por la suiza, es el medio idóneo para quebrantar el monopolio representativo: el otorgar a una fracción del cuerpo electoral la facultad de someter a la consulta directa del mismo la decisión sobre un determinado asunto, libera al referéndum de la tutela a que antes no referiamos, y da a esta institución su sentido más genuino. El continuum iniciativa popular-referéndum garantiza la autonomía, con respecto a los órganos representativos, de la consulta directa.

Como escribe CRUZ VILLALÓn, advirtiendo de las virtualidades de un tipo específico del mismo, el abrogativo: «es el más difundido intento de conciliación entre el ejercicio directo de la soberanía popular y la democracia representativa: los representantes sólo son legisladores en tanto su obra es ratificada tácitamente por el pueblo, es decir, a menos que éste, normalmente en su determinado plazo, inicie un proceso dirigido a la derogación de la ley aprobada por los representantes" ${ }^{34}$.

Sin duda, la supresión de esta iniciativa popular, que sin embargo

31 En el Anteproyecto de la Ponencia constitucional (BOC de 5 de enero de 1978) esta iniciativa se refería a la aprobación de leyes votadas y aún no sancionadas y a las decisiones políticas de especial trascendencia. En el texto que pasó a la Comisión de Asuntos Constitucionales, una vez incorporados o no los votos particulares de los grupos parlamentarios (BOC de 1 de abril de 1978) la iniciativa de las comunidades sólo se entendía dirigida a la derogación de leyes en vigor. En la citada Comisión, Alianza Popular propuso una enmienda (número 35) por la que se excluia esta iniciativa. Las minorías vasca y catalana (enmiendas 630 y 157) propusieron en la Comisión de Asuntos Constitucionales que se redujera a dos el número de las comunidades que podian instar el referéndum. Finalmente la enmienda in voce de SOLE TURA excluyó esta iniciativa.

32 En un voto particular presentado por el grupo comunista al anteproyecto consensuado por la ponencia, pero no incorporado al texto discutido en la Comisión de Asuntos Constitucionales, se establecía la supresión de esta iniciativa popular. La UCD presentó en la Comisión referida una enmienda por la que la iniciativa se reservaba exclusivamente a las Cámaras. El asunto se resolvió por la incorporación al texto de la reiteradamente citada enmienda de SOLE TURA.

${ }_{33}$ La italiana en su artículo 75 establece la convocatoria de referéndum popular para otorgar la aprobación total o parcial de una ley o un acto con valor de ley, cuando sea requerido por lo menos por quinientos mil electores.

34 Cruz VILlalon, ob. cit., pág. 147. 
se reconocía parcialmente en el texto inicialmente consensuado, es la restricción de mayor importancia que se le ha hecho a la identidad democrática en nuestro ordenamiento constitucional. La opción adoptada por los constituyentes ha tenido y tendrá consecuencias de extraordinaria importancia politica. Temas centrales hubieran suscitado iniciativas populares con vistas a la consulta directa: la solución dada a la cuestión del aborto, hubiera podido verse frustrada, teniendo en cuenta la inclinación del sustrato social español, por los valores religioso-católicos, lo que presumiblemente hubiera afectado a importantes sectores de votantes de partidos a priori pro-abortistas ${ }^{35}$.

El tema de la incorporación de España a la OTAN ilustra las consecuencias de esta detracción a la democracia de identidad, obtenida a través de la exclusión de la iniciativa popular: el Gobierno de la Unión de Centro Democrático, presidido por Calvo Sotelo, con el necesario respaldo parlamentario en ambas Cámaras, propició la entrada -casi a hurtadillas- de España en la Organización Atlántica el 30 de mayo de 1982. Esta decisión sustentada por la mayoría parlamentaria, se tomó, como es sabido, excluyendo la posible participación ciudadana directa, a pesar de que, según múltiples sondeos de opinión, ésta se mostraba a todas luces partidaria de que la entrada o no en la Organización se decidiera por referéndum ${ }^{36}$.

El Gobierno de la mayoría parlamentaria hizo caso omiso de los múltiples muestreos de opinión, que advertían de la existencia de una holgada mayoría en la población contraria al ingreso ${ }^{37}$, lo que no hubiera sido posi-

35 En este sentido resulta de gran interés la encuesta de opinión patrocinada por "Cáritas" y publicada en el diario YA el día 10 de noviembre de 1980. El interés de la misma es doble. Por un lado, los datos que aporta: el 59,2 por 100 de los habitantes de Madrid capital, estarian en contra del aborto en cualquier caso, el 33,8 por 100 lo admitirían en circunstancias especiales y el 7 por 100 lo acepta en cualquier caso; en un contexto en el que el 1,2 por 100 se declara de extrema derecha, el 9,7 por 100 de derechas, el 24,6 por 100 de centro, el 31,5 por 100 de izquierdas y el 3,5 por 100 de extrema izquierda.

Pero por encima de estos datos, inevitablemente condicionados por la índole de la entidad que patrocina el estudio de opinión, se pone de manifiesto las enormes posibilidades que tendría una iniciativa promovida en los medios eclesiásticos, cuyo desarrollo en forma de campaña publicitaria tendría como piedra de toque, precisamente, las encuestas de opinión. El referéndum celebrado en Irlanda el 9 de septiembre de 1983, para introducir en su Constitución un artículo que prohibe el aborto, que fue convocado por el Gobierno de aquel país, sirve de referencia a la hora de hacer previsiones sobre lo que hubiera podido ocurrir aquí. Dos tercios de los votantes se manifestaron a favor de la reforma constitucional. El gran número de abstenciones que rondó el $\mathbf{5 0}$ por 100, puso en todo caso de manifiesto la capacidad de la Iglesia Católica, que intervino con mucha intensidad en la campaña, para inducir al activismo religioso a sus acólitos, frente a la pasividad laica.

36 Según una encuesta de Sofemasa publicada en El País el 18 de octubre de 1981, el 69 por 100 de los interrogados consideraba que el referéndum era el método adecuado para decidir la integración española en la Alianza Atlántica. Los resultados del sondeo de Metra/Seis, publicados por el Diario 16 del 29 de junio de 1981, dan el mismo porcentaje de partidarios del referéndum.

37 A modo de ejemplo, citaremos algunos muestreos. El publicado por Diario 16 el día 29 de octubre de 1980 daba como partidarios del ingreso a un 20,4 por 100 , y como 
ble de haberse constitucionalizado la iniciativa popular para la convocatoria de referéndum sobre decisiones de especial trascendencia.

Hay un hecho que conviene destacar: como es sabido, con anterioridad al ingreso, la oposición de izquierdas realizó una intensa campaña en contra del mismo, a cuyo objeto fueron presentadas 500.000 firmas por parte del PC y 600.000 por el PSOE, solicitando una consulta popular sobre el mismo, lo que hubiera bastado en caso de haberse institucionalizado la iniciativa, tan combatida en las constituyentes por esos grupos, para provocar la consulta directa y, eventualmente, el rechazo al ingreso en la organización militar. El predominio absoluto del principio de representación sobre el de identidad se siguió haciendo patente en el problema de las relaciones del Estado español con la OTAN: el Gobierno socialista, después de su triunfo electoral en octubre de 1982, fue retrasando su sometimiento a consulta popular, a pesar de sus promesas electorales y de que los sondeos de opinión seguían denunciando la existencia de mayorías contrarias al ingreso ${ }^{38}$. Es reseñable la relativa incoherencia de partidos como el PSOE y el PC que en el transcurso del período constituyente se opusieron, en ocasiones con cierto radicalismo, a la democracia de identidad, para inmediatamente exigirla con el asunto del ingreso en la OTAN. Se ha dicho relativa, puesto que la actitud del PSOE, una vez convertido en el partido del Gobierno, ha hecho prácticas las tesis defendidas en el debate constituyente.

En definitiva, con su regulación final este tipo de referéndum consultivo ha sido anulado en su sentido más sustancial. Una a una las innovaciones incorporadas al mismo a lo largo del proceso constituyente -incluido el desarrollo legislativo de la norma fundamental- han ido cercando el contenido de la institución, en beneficio de la mediación parlamentaria. La referencia al debate constituyente resulta ilustrativa, puesto que el punto del que se partía, el anteproyecto de la ponencia constitucional y el resultado final, con casi extremos opuestos del abanico de posibilidades que se podía ofrecer a la democracia referendaria para ser constitucionalizada como contraposición al predominio representativo.

contrarios a un 36,4 por 100 , mientras que el resto se abstenía o no opinaba. En el ya citado sondeo de Sofemasa, del 18 de octubre de 1981 , el 44 por 100 rechazaba la entrada en la Alianza, el 14 la aceptaba, el 26 por 100 no había formado criterio, el 10,2 por 100 afirmaba su intención de votar en blanco y el resto no contestaba. En este mismo estudio de Metra/Seis de 29 de junio de 1981, los resultados fueron los siguientes: 39 contrarios al ingreso; 27 partidarios; el resto, no sabe, no contesta.

${ }_{38}$ El último muestreo del que tenemos noticia es el realizado por el instituto Metra/Seis, entre los dias 11 y 15 de abril de 1983 . El 54,3 por 100 de los encuestados consideraba vigente la celebración del referéndum; el 8 por 100 se pronunciaba por la «integración plena", el 52,5 por 100 era partidario de la "retirada total de la OTAN", el 26,8 de la «retirada del bloque militar" y el 12,8 por 100 no contesta.

Hay que tener en cuenta, sin embargo, que estos datos se refieren sólo al 50,8 por 100 que declaraba saber exactamente lo que era la OTAN. Lo que hace suponer que el sentido de la "campaña de información" que se dé en el futuro sobre la misma puede ser absolutamente decisiva. 


\section{Los referendos autonómicos}

Pasaremos ahora a tratar de los referendos autonómicos. Bajo este nombre se conocen un conjunto de consultas populares previstas en la Constitución, circunscritas al cuerpo electoral de una Comunidad Autónoma ya constituida, o en trance de serlo.

En el artículo 151.1 de la norma constitucional queda establecido un referéndum para la ratificación de la iniciativa del proceso autonómico, de acuerdo con el modelo establecido en el mismo, que precisa del voto afirmativo de la mayoría absoluta de los electores de cada provincia ${ }^{39}$. Esta ratificación es paso obligado en la creación de Comunidades de Autonomía. La Ley Orgánica del 18 de enero de 1980 desarrolla esta especie de referéndum. Esta ley fue modificada para añadir dos párrafos al apartado cuarto del artículo 8 , que trata precisamente de la ratificación, por consulta popular directa, de la iniciativa autonómica, que fueron incorporados, como es sabido, tras el fracaso en la provincia de Almeria, de la celebrada el 20 de febrero de $1980^{40}$.

Otro tipo encuadrable en este apartado es el de la ratificación del Estatuto de Autonomía, elaborado por la Asamblea de Parlamentarios del territorio en vías de autonomizarse, después de haber sido concertado con la Comisión de Asuntos Constitucionales del Congreso ${ }^{41}$. La posibilidad de que este último requisito no se cumpla, determina la tramitación del Estatuto como proyecto de ley ante las Cortes Generales que, una vez aprobado por éstas, se somete, asimismo, a referéndum del cuerpo electoral del ámbito territorial del proyectado Estatuto.

Por otro lado, la modificación de los Estatutos de las Comunidades que hubieran accedido a la autonomía por la via del artículo 151, precisa de la ratificación por referéndum (art. 152, párrafo 2).

Por último, también se condiciona a referéndum la "validez" de la iniciativa del Organo foral de Navarra para la incorporación de la misma al "Consejo General Vasco" o al régimen autonómico que le sustituya (Disposición Transitoria cuarta).

39 Artículo 151.1. «No será preciso dejar transcurrir el plazo de cinco años, a que se refiere al apartado 2 del artículo 148, cuando la iniciativa del proceso autonómico sea acordada dentro del plazo del artículo 143. 2, además de por las Diputaciones o los órganos interinsulares correspondientes, por las tres cuartas partes de los municipios de cada una de las provincias afectadas que representen, al menos, la mayoría del censo electoral de cada una de ellas y dicha iniciativa sea ratificada mediante referéndum por el voto afirmativo de la mayoría absoluta de los electores de cada provincia en los términos que establezca una ley orgánica."

40 Sólo un 47,16 por 100 del censo electoral de la provincia se pronunció a favor de la iniciativa autonómica. nica

41 Artículo 151, apartado 2, número 3 de la Constitución. Artículo 9 de la Ley Orgá- 
En la línea que nos hemos marcado, no entraremos a fondo en la problemática jurídico-constitucional que suscitan estas fórmulas ${ }^{42}$. La expectativa de identidad democrática que crean es sólo relativamente alta, puesto que se trata de consultas que se limitan a corroborar o no decisiones previamente tomadas por órganos legislativos ${ }^{43}$. Además, en este caso, la contradicción representación-identidad se ve mediada por aquella que se da entre Estado y Comunidades Autónomas.

De hecho, si en materias relacionadas con la democracia directa, el debate había sido protagonizado por Alianza Popular, en lucha con el consenso más o menos cerrado de UCD, PSOEy PCE, en este punto concreto se trasladó al enfrentamiento entre los nacionalistas vascos y catalanes, y el bloque formado por los partidos de una orientación panestatal.

En el anteproyecto de la ponencia constitucional no figuraba el referéndum para ratificar la iniciativa del proceso autonómico, (no se contemplaba la doble vía como en el texto final) ni en el de ratificación de la reforma de los estatutos. En el dictamen de la Comisión de Asuntos Constitucionales aparece ya la regulación actual.

En la citada Comisión, las minorías nacionalistas catalana y vasca propusieron enmendar el artículo 131 del proyecto que preveían la celebración del referéndum en los territorios preautonómicos, después de elaborado el Estatuto por la Asamblea de parlamentarios y antes de cualquier convalidación de índole estatal. En la exposición de motivos de una enmienda vasca se razonaba esto así: "una vez que el proyecto haya sido aprobado por los parlamentarios -de los territorios preautónomosy antes de seguir cualquier otro trámite, en un juego democrático auténtico, es preciso conocer la voluntad soberana del pueblo, si de verdad se quiere convertir en realidad la afirmación de que la soberanía reside en aquél» ${ }^{44}$.

Esta reivindicación de la consulta directa como expresión más auténtica de la soberanía popular probablemente tenía que ver, más que con la adscripción al principio de identidad democrática, con las aspiraciones generales de autodeterminación; se quería anteponer la decisión refendataria del

42 El artículo citado de Enrique Linde Paniagua y Miguel Herrero Lera dedica un extenso epígrafe a su análisis (págs. 40 y siguientes).

43 Asamblea de Parlamentarios y Comisión de Asuntos Constitucionales del Congreso en la iniciativa autonómica del artículo 151; Organo Foral Navarro y en lo que afecta a la reforma de los Estatutos, hay que estar a lo que en ellos se diga (152.2 Constitución; 10 de Ley Orgánica). Estos se refieren a dicha reforma, especificando la necesidad de aprobación por mayorias reforzadas de sus respectivos órganos legislativos, previa al referéndum (art. 56 del Estatuto de Autonomia para el País Vasco; artículo 56 del Estatuto de Autonomía para Galicia).

44 El texto citado literalmente procede de la enmienda 652 del Grupo parlamentario vasco. En el mismo sentido y ante la Comisión de Asuntos Constitucionales del Congreso se presentaron otras: la número 567 del grupo mixto y la 180 del catalán. 
cuerpo electoral del territorio autónomo a la de los órganos representativos del Estado ${ }^{45}$. En el texto finalmente aprobado no se recogió la modificación propuesta por los nacionalistas. Pero la inclusión del referéndum de iniciativa autonómica fue una victoria de la participación directa en el debate constituyente. Hay que entenderla, sin embargo, como una cesión estatal no excesivamente relevante, pero conveniente en el contexto de la negociación con los intereses autonómicos. Por otro lado, la modificación referida del 16 de diciembre de 1980, que afecta a la Ley Orgánica del Referéndum, en definitiva restó importancia a esta consulta popular, pues establece que en caso de no resultar positiva en una o varias provincias, la ratificación refendataria de la iniciativa podía ser sustituida por las Cortes Generales a través de una Ley orgánica ${ }^{46}$.

Por encima de todo, el decisivo punto 32 del artículo 149 de la Constitución y el 2 de la Ley Orgánica del Referéndum garantizan la fiscalización última del Estado sobre estas consultas populares en el ámbito autonómico, al determinar como competencia exclusiva del Estado «la autorización para la convocatoria de consultas populares por vía del referéndum". Es decir, que aunque el referéndum se circunscriba a un territorio autónomo y se inste por órgano del mismo, se exige un acto estatal de autorización, para el que, según se desprende del artículo segundo (punto 2) de la Ley Orgánica, es competente el Gobierno de la Nación. En el anteproyecto de Constitución elaborado por la ponencia, no aparece esta autorización entre las materias sobre las que tiene exclusiva competencia el Estado (art. 136): fue introducido por enmienda in voce en la Comisión de Asuntos Constitucionales.

Obviamente, la autorización se requiere para todos los referendos autonómicos obligatorios a los que nos hemos referido arriba. Sin embargo, su regulación en la Ley Orgánica plantea problemas. Cuando alude -en el artículo 8, apartado 3- específicamente al referéndum de ratificación de la iniciativa autonómica por la vía del artículo 151, indica que, una vez acreditada la iniciativa, «el Gobierno procederá a la convocatoria del referéndum». Lo mismo parece que estipula el artículo 9 en referencia al de ratificación del Estatuto de Autonomía ${ }^{47}$.

45 De hecho, los nacionalistas no combatieron la progresiva limitación del uso de mecanismos de democracia semi-directa que se fue produciendo en las sucesivas discusiones del texto constitucional.

46 La modificación al apartado cuarto añadia los siguientes párrafos: "Esto no obstante, la iniciativa autonómica prevista en el artículo 151 se entenderá ratificada en las provincias en las que se hubiere obtenido la mayoría de votos afirmativos previstos en el párrafo anterior, siempre y cuando los votos afirmativos hayan alcanzado la mayoría absoluta del censo de electores en el conjunto del ámbito territorial que pretenda acceder al autogobierno. Previa solicitud de la mayoría de los Diputados y Senadores de la provincia o provincias en las que no se hubiera obtenido la ratificación de la iniciativa, las Cortes Generales mediante Ley orgánica podrá sustituir la iniciativa autonómica prevista en el artículo 151 siempre que concurran los requisitos previstos en el párrafo anterior.

47 Artículo 9.1. «La aprobación por referéndum de un Estatuto de Autonomía de acuerdo con lo establecido en los números 3 y 5 del apartado 2 del artículo 151 de la Cons- 
Esto, por un lado, entra en contradicción -por lo menos en sus términos- con el artículo 62 del texto constitucional, que confiere al Rey la facultad de convocar a referéndum, lo que reitera el apartado 3 del articulo 2 de la propia Ley Orgánica. Por otro, choca con el ya citado apartado 2 de este mismo artículo que habla, simplemente, de autorización del Gobierno.

Pero lo que de verdad es trascendente en el artículo 149, apartado 32 , es el hecho de que, obviamente, impide que los entes autonómicos puedan, discrecionalmente, convocar referendos facultativos en su ámbito territorial, a pesar de que el derecho comparado no es ajeno a esta posibilidad. En la Constitución italiana -que a lo largo de este artículo nos ha servido de referente- son posibles los referendos intrarregionales sin intevención estatal, de acuerdo con su artículo 123.

Aunque cualquier valoración resulte compleja en este marco, no hay duda de que el precepto citado impone limitaciones superpuestas: a la voluntad del cuerpo electoral, en su expresión directa, y a la propia autonomía del ente territorial.

La convocatoria "autonómica" de referendos podría determinar cambios sustanciales en el panorama político de las Comunidades Autónomas. Sólo hay que pensar en el movimiento de opinión generado en el País Vasco en torno a la central nuclear de Lemoniz: la convocatoria de una consulta popular sobre el tema por el gobierno vasco -el Partido Nacionalista Vasco se ha mostrado partidario del mismo- que no requisiera la ulterior aprobación estatal, hubiera podido llevar a la demolición de la central nuclear.

De haberse ampliado los límites de la democracia de identidad para las Comunidades Autónomas, hasta el punto de admitirse la iniciativa popular en la convocatoria de referendos en ese ámbito, el tema de la incorporación de Navarra al País Vasco, por ejemplo, se hubiera resuelto muy probablemente con la total desvinculación de aquélla de la comunidad vasca, ya que los sucesivos sondeos realizados hasta ahora muestran una opinión mayoritaria en ese sentido ${ }^{48}$. De todas formas, no podemos conti-

titución requerirá la previa comunicación al Presidente del Gobierno del texto resultante en el primer caso o del texto aprobado por las Cortes Generales en el segundo. Recibida la comunicación, se procederá a la convocatoria del referéndum dentro del plazo de tres meses, en las provincias comprendidas en el ámbito territorial del proyectado Estatuto.

48 En este sentido, cabe citar el realizado por el antiguo Instituto de la Opinión Pública, en noviembre de 1977, que mostraba a un 20 por 100 partidario de la integración en el País Vasco, a un 47 por 100 contrario a la misma y a un 33 que permanecía aún indeciso. El sondeo realizado por Sofemasa para el diario El Pais publicado el 6 de diciembre de 1977 , concluía en que un 57,3 por 100 de los navarros no se mostraba partidario de la integración en Euzkadi, prefiriendo un régimen propio de autonomía. Un 40,1 por 100 se mostraba partidario de la integración a todos los efectos. Un estudio más reciente «Panel autonómico de Navarra 83n, realizado por el CITEP (febrero de ese año) daba los siguientes resultados: Partidarios de la integración inmediata, un 9,8 por 100; partidarios de 
nuar sin, por lo menos, apuntar algunas de las complejas reflexiones, que en relación con el tema de la oposición identidad-representación, puede suscitar este asunto en concreto. De hecho, la imposición de la voluntad mayoritaria expresada en referéndum desencadenaría una situación aún más conflictiva que la actual que, incluso, pondria en duda la propia subsistencia de Navarra como entidad territorial unida. De ahi el que la mesurada actitud de una gran parte de la representación política en el gobierno foral - UCD y PSOE - que se muestra partidaria de una "vinculación» progresiva a través de la vía del artículo 22 del Estatuto de Guernica (que trata de las relaciones del País Vasco con "otros territorios forales") sea comprensible.

\section{El referéndum para la reforma constitucional}

En nuestra Constitución, el uso del referéndum en la reforma constitucional se limita a dos supuestos: el primero, tiene carácter optativo y puede ser convocado a iniciativa de una décima parte de los miembros de cualquiera de las Cámaras, sólo en el caso de que se trate de la ratificación de una mera "reforma" constitucional (arts. 167 de la Constitución y 7 de la Ley Orgánica sobre las distintas modalidades de referéndum) ${ }^{49}$.

El segundo tipo de referéndum se da en el caso de «revisión» total o parcial de la Constitución, pero que afecte al Título preliminar, al Capitulo segundo, a la Sección primera del Título I y al Título II. En este supuesto se establece un referéndum preceptivo, que ratifique o no la reforma ya aprobada por las Cortes ${ }^{50}$.

Obviamente, la incidencia de la democracia de identidad por la vía de referéndum constitucional queda raquítica si la comparamos con el ordenamiento suizo. En éste se prevé, por un lado, la consulta popular obligatoria en toda innovación legislativa que pueda afectar a la Constitución, lo que ha tenido una interpretación extensiva, y, por otro, un tipo de iniciativa popular, de conformidad con la cual, cien mil ciudadanos pueden provocar un

una integración a largo plazo, pero conservando las instituciones y los derechos históricos, un 13,7 por 100; partidarios de la integración a medio plazo y sin conservar sus instituciones un 1,3; contrarios a la integración de Navarra en la Comunidad Autónoma Vasca, un 65 por 100.

49 Artículo 167. Apartado 3. Aprobada la reforma por las Cortes Generales, será sometida a referéndum para su ratificación cuando así lo soliciten, dentro de los quince dias siguientes a su aprobación, una décima parte de los miembros de cualquiera de las Cámaras.

so Artículo 168, apartado 1. "Cuando se propusiere la revisión total de la Constitución o una parcial que afecte el Título preliminar se procederá a la aprobación por mayoría de dos tercios de cada Cámara, y a la disolución inmediata de las Cortes". Apartado 3 “Aprobada la reforma por las Cortes Generales, será sometida a referéndum para su ratificación". 
referéndum en el que se plantee una enmienda a la Constitución ${ }^{51}$. Sin embargo, - al margen del excepcional constitucionalismo suizo-, la formulación española es similar a la italiana o la francesa. Aunque la regulación italiana, por un lado, se inclina más hacia la participación directa, al admitir la iniciativa popular para la celebración de referendos sobre reformas ya aprobadas por las Cámaras, por otro, la restringe —en comparación con la española-, al no contemplar el referéndum preceptivo en el caso de revisión total o parcial en determinados supuestos de importancia, como en la Constitución española ${ }^{52}$. Tampoco la Constitución francesa concede al referéndum una mayor participación en la reforma constitucional: el Presidente de la República decide si ésta debe ser sometida a consulta popular o al Parlamento, en el que deberá obtener una mayoría de dos tercios.

También en la cuestión de la reforma constitucional el proceso constituyente se concluyó con la restricción de la práctica referendaria. En el informe dictaminado por la ponencia constitucional (art. 158,3), se especificaba que toda reforma seria sometida a referéndum para su ratificación ${ }^{53}$. En realidad, en aquel texto no se distinguía entre reforma y revisión total de la Constitución. Los debates en la Comisión de Asuntos Constitucionales lo ajustaron a la regulación actual. Recordemos, además, que por enmienda de Cisneros Laborda (UCD) se incluyó, entre las materias vetadas a la iniciativa legislativa popular, la reforma constitucional, lo que contemplaba el anteproyecto de la ponencia.

No obstante, cotejados el referéndum para la reforma constitucional con el resto de los contemplados en nuestro ordenamiento político,

51 Artículos 120 y 121 de la Constitución Federal. El artículo 120 regula la reforma total que se podrá dar por la iniciativa de 100.000 electores, pero que exigirá en todo caso la votación directa del pueblo suizo. En el artículo 121 se regula la reforma parcial que podrá tener lugar por la via de la iniciativa popular y, que también provoca finalmente una consulta directa.

52 Artículo 138. "Las leyes de revisión de la Constitución y las demás leyes constitucionales serán adoptadas por cada Cámara con dos sucesivas deliberaciones a intervalos no menores de tres meses y se aprobarán por mayoría absoluta de los componentes de cada Cámara en la segunda votación". Dichas leyes se someterán a referéndum popular, cuando dentro de los tres meses de su publicación, lo solicite una quinta parte de los miembros de una de las Cámaras, o quinientos mil electores o cinco consejos regionales. La Ley sometida a referéndum no se promulgará mientras no sea aprobada por la mayoría de votos válidos. No hay lugar a referéndum si la ley ha sido aprobada en la segunda votación por cada una de las dos Cámaras con la mayoría de los dos tercios de sus componentes".

53 El grupo socialista presentó ante la Comisión una enmienda (n. ${ }^{\circ} 373$ ) al artículo 158.3 de la ponencia, según la cual sólo se someteria la reforma a referéndum si así lo solicitaba un quinto de los miembros de una de las Cámaras. La enmienda se fundamentaba en que la exigencia de referéndum para toda reforma sería "un factor de despolitización", y que en las reformas constitucionales de "carácter técnico" y "no político", no parecía conveniente el uso del referéndum. El grupo parlamentario comunista presentó una enmienda al mismo artículo en la que, además de cambiar el procedimiento haciéndolo menos flexible, se estipula que el referéndum solo tendría lugar si la reforma no obtuviera una mayoría de dos tercios en las dos Cámaras (Esto es una copia del citado art. 138 de la Constitución italiana). 
resulta aquél muy favorecido. En la práctica será muy difícil que cualquier reforma constitucional no dé lugar al mismo; siempre habrá una minoria parlamentaria -que llegue al 10 por 100 - dispuesta a contrastar la reforma con la expresión directa de la opinión pública. Claro que la intención política de estos referendos no se fundamenta tanto en que sirvan de cauce a la democracia directa como "en acentuar el carácter rígido de la Constitución, en línea con las mayorías cualificadas y, en su caso, la disolución de las Cámaras» ${ }^{54}$.

El debate constituyente vino a confirmar aquello de que «la cuestión del referéndum constitucional ha sido siempre mucho menos polémica quizá porque reconciliaba la noción democrática de la participación directa con la noción conservadora de la rigidez constitucional. Quizá también porque la afirmación ocasional y prácticamente excepcional de la soberanía popular mediante el voto de la Constitución no alteraba en absoluto el funcionamiento regular de las instituciones representativas ni afectaba básicamente al curso del procedimiento legislativo ordinario" 55 .

\section{Facultades concedidas a los partidos en la convocatoria de referendos}

Hay que reseñar una última limitación, que con carácter general afecta a todos los tipos de referendos. La encontramos en la Ley Orgánica que en su artículo 11, apartado 2, especifica que las facultades concedidas en el régimen electoral general a los Partidos, federaciones, coaliciones y agrupaciones de electores se entienden referidas a los partidos con representación parlamentaria, o a aquellos que hubieran obtenido más de un 3 por 100 de los votos en las últimas elecciones generales. El artículo 14, apartado 1, por su parte, señala que durante la campaña electoral los medios de comunicación del Estado concederán el uso de espacios gratuitos a los grupos políticos con representación parlamentaria. Con estas disposiciones se facilita el protagonismo en el referéndum de los partidos -que ya lo ejercen a través de la representación política- y se potencia su capacidad de incidencia en la formación de la opinión pública con vistas a aquél. Si de lo que se trata con la consulta directa -cuanto menos mediada sobre todo por instancias institucionalizadas mejor-, es de ofrecer un contrapunto a la determinación de la voluntad del Estado a través del mecanismo representativo, el conceder a los partidos, que controlan absolutamente aquél, ese privilegio es un absoluto contrasentido: desvela cualquier duda sobre la intención del legislador constituyente,

Cruz Villalón, ob. cit., pág. 164.

Julian Santamaría, Participación política y democracia directa, ob. cit., pág. 755. 
que no es otra que la de restringir cualquier expectativa real de participación directa.

\section{LA JUSTICIA POPULAR Y EL CONCEJO ABIERTO}

Al resto de las manifestaciones de la democracia y de la participación directa de los ciudadanos nos referiremos brevemente.

En cuanto a la Justicia popular, nuestra Constitución aborda en el artículo 125, la posibilidad de que el pueblo participe en la administración de la justicia a través de la institución del Jurado, "en la forma y con respecto a aquellos procesos penales que la Ley determine". Antes de su paso por la Comisión de Asuntos Constitucionales del Congreso, la participación del pueblo quedaba enunciada genéricamente; no se restringía a la figura del Jurado. Más tarde nos referiremos al tema.

Dentro del Capítulo II del Título $8 .^{\circ}$ hay una mención al Concejo abierto, única forma de democracia directa explícitamente reconocida, pero con la indicación de que "la ley regulará las condiciones en las que proceda el régimen de Concejo abierto". En estos términos se resuelve la polémica mantenida, esencialmente entre AP y UCD; la primera, partidaria de que el Concejo no se limite a una especie de capítulo a extinguir, y la segunda, de que efectivamente se reduzca a los casos en los que se venía observando esta tradición.

\section{LA RESTRICCION DEL PRINCIPIO DE IDENTIDAD}

Lo dicho muestra el carácter limitado y marginal de las manifestaciones del principio de identidad y de la democracia no representativa en nuestra Constitución. Aunque se autodeclara mixta, desarrolla insuficientemente los métodos para contrarrestar con cierta eficacia aquel principio. El referéndum consultivo, que aparece como la pieza clave en la consecución de ese objetivo, apenas trastoca la dinámica democrática representativa. Con él se ha constitucionalizado algo que era una mera práctica en los más estrictos sistemas liberal-parlamentarios, anteriores a la institucionalización de los métodos de democracia semi-directa, que en ocasiones recurrían a la consulta popular.

Lo cierto es que se ha creado un referéndum más orientado a la legitimación que a la decisión, lo que resta calidad a la institución desde una perspectiva de identidad democrática. Los que establecen con carácter preceptivo (autonómicos, de reforma constitucional) sirven para la rati- 
ficación de decisiones ya adoptadas por un órgano legislativo. El consultivo del artículo 92, por su parte, parece más bien abocado a servir de cobertura plebiscitaria de la mayoría gubernamental en decisiones especialmente comprometidas.

En definitiva, la posibilidad de que el pueblo participe directamente en los asuntos públicos, preconizada solemnemente en el artículo 23.1, queda comprometida en el propio texto que restringe radicalmente la virtualidad de los mecanismos de democracia semidirecta que instituye. La propia contradicción en el texto nos advierte del carácter ideológico-declarativo del derecho público subjetivo a la participación directa, vetado en su propio desarrollo.

En el texto constitucional del 78 contrasta el amplio espectro de derechos fundamentales liberales y de tipo social que se garantizan al individuo, con el escaso reconocimiento efectivo del derecho a expresar sin intermediarios su propia voluntad de modo vinculante sobre un asunto determinado. La Constitución, en este aspecto, renueva aquella máxima del despotismo ilustrado: todo para el pueblo, objeto de asistencia social y protegido exhaustivamente en cuanto a la seguridad y libertad personales, pero sin el pueblo, por lo menos en lo que hace a su exclusión de la participación directa en los asuntos públicos.

\section{LA INTERPRETACION EXTENSIVA DEL PRINCIPIO REPRESENTATIVO}

Un examen general de la norma fundamental pone de manifiesto el especial empeño en vincular todas las instituciones al principio representativo. Ejemplo de esto es la constitucionalización de la concurrencia de los partidos a la formación de la voluntad popular (art. 6). Como indica MANUEL RAMÍREZ ${ }^{56}$ la estricta opción por la democracia representativa la evidencia el especial énfasis que puso el legislador al indicar tajantemente que los partidos "son instrumento fundamental para la participación política». En este sentido, nuestro ordenamiento político reproduce, con cierto extremismo, la tendencia del constitucionalismo europeo de la postguerra, que asi se avino a formalizar lo que era una contundente realidad ${ }^{57}$.

56 Manuel Ramirez, ob. cit., págs. 19 y 20.

57 Tanto la Constitución francesa de 1958 (art. 4), como la italiana (art. 49), o la Ley Fundamental de Bonn de 1949 (art. 121), reconocen e institucionalizan la concurrencia de los partidos a la formación de la voluntad popular. Sobre este tema ver, Miguel HERRERO, "La constitucionalización de los partidos políticos en el derecho comparado. Algunos textos y leyes ordinarias representativas", en Los partidos políticos en España. Ed. de Raúl Mo. RODO y otros. Labor. Barcelona, 1979. 
También la explícita referencia al carácter no imperativo del mandato de diputados y senadores del artículo 67.2, pone de manifiesto la actitud resuelta del legislador, que no quiere dejar dudas sobre el carácter de la representación que se constitucionaliza. Esta intención aparece también en las normas fundamentales de Italia, Francia y Alemania, que formulan expresamente también la independencia de los parlamentarios en el ejercicio de su mandato ${ }^{58}$.

El precepto establecido en el 67.2 es superfluo desde el punto de vista práctico: no cabe hoy restablecer, por evidentes razones técnicas, el mandato imperativo en el sentido tradicional al que el término hace referencia.

Sin embargo, sí es hoy posible una restricción al libre mandato por otra vía: la de condicionar el cargo representativo a la permanencia en el partido por el que el diputado se presentó a las elecciones.

La Constitución no se refiere al tema. Los reglamentos del Congreso y del Senado, cuando señalan las causas por las que el diputado o senador pierde la condición de tal, no se refieren a la baja en el partido. Las sentencias 5/1983 de 4 de febrero de 1983 y 10/1983 de 21 de febrero ${ }^{59}$, despejaron cualquier duda al respecto en lo que se refiere al gobierno municipal, al admitir el recurso de amparo presentado por el Alcalde de Andújar y varios concejales del Ayuntamiento de Madrid, respectivamente, y declarar derogado el artículo 11.7 de la Ley de Elecciones Locales del 7 de julio de $1978{ }^{60}$ en lo que se refiere a que la expulsión del partido provoca el cese en el cargo de Concejal ${ }^{61}$.

58 El artículo 67 de la Constitución de la República Italiana establece que, cada miembro del Parlamento representa a la Nación y ejerce sus funciones sin vínculo de mandato. El 27 de la Constitución francesa estipula que "todo mandato imperativo es nulo". La Ley Fundamental de Bonn, por su parte, dice que los diputados serán representantes del pueblo en su conjunto, no ligados a mandatos ni instrucciones, y sujetos únicamente a su conciencia (art. 38).

59 Boletín Oficial del Estado del 9 de marzo de 1983 y del 23 del mismo mes y año respectivamente.

60 El artículo 11.7 dice asi: "Tratándose de listas que representan a partidos politicos, federaciones o coaliciones de partidos, si alguno de los candidatos electos dejara de pertenecer al partido que le presenta, cesará en su cargo y la vacante será atribuida en la forma establecida en el número anterior. El que así accediera ocupará el puesto por el tiempo que restare de mandato".

61 La jurisprudencia constitucional sobre el tema fue motivada por sendos recursos de amparo, el primero interpuesto por el ex alcalde de Andújar y el segundo por cinco concejales del Ayuntamiento de Madrid. En líneas generales los recurrentes solicitaban ser repuestos en sus cargos, dejándose sin efecto los actos de los órganos locales y las sentencias jurisdiccionales que declararon el cese en su condición de representantes y asimismo la declaración de inconstitucionalidad sobrevenida del artículo 11.7 de la Ley de Elecciones Locales de 17 de julio de 1978. Las sentencias declararon la nulidad de los acuerdos municipales, la resolución de la Junta Electoral de la zona de Madrid y de las sentencias de to contencioso, restableciendo el derecho de los demandantes al ejercicio de los cargos representativos. Las sentencias declaran vulnerado por el art. 11.7 el derecho de los ciudadanos a participar en los asuntos públicos mediante representantes y el de los representantes. 
La jurisprudencia del alto tribunal, contribuye con ello, a acentuar la orientación de nuestro sistema político hacia la formulación más estrictamente liberal de la representación. Las sentencias referidas, que en sus considerandos se acogen explícitamente a aquélla ${ }^{62}$, favorecen la independencia del diputado, pero en perjuicio del derecho a la participación política establecido genéricamente en el artículo 23.1 de la Constitución.

Obviamente, la revocación del diputado por el partido no es comparable con aquella manifestación de la democracia directa, consistente en el derecho de una parte del cuerpo electoral a solicitar la destitución de un representante o funcionario electivo ${ }^{63}$.

Sin embargo, su supresión limita la participación política del ciudadano, en un sistema electoral como el nuestro de listas cerradas y con una organización sólida y continua de los partidos, puesto que la motivación que prima por encima de cualquier otra en el acto electoral, es la de apoyar a una $u$ otra de esas opciones políticas organizadas ${ }^{64}$.

Se puede argumentar que el contenido del artículo 11.7 de la ley citada, refuerza el papel preponderante de los partidos y, consiguientemente, la mediación por los mismos de la participación política. No obstante, ante esa irreversible situación de hecho que llega hasta el punto de que la opción periódica entre uno $u$ otro partido calma las expectativas de participación del electorado, la concesión de la competencia de revocación a los partidos sobre sus diputados electos no contradice a aquélla, sino todo lo contrario. Con ello se preserva por lo menos el único intersticio participa-

mismos a mantenerse en sus funciones (art. 23.2). También consideran como no válido constitucionalmente la atribución a un órgano no público de la facultad de determinar por sí mismo el cese de los representantes. La sentencia 5/1983 de 5 de febrero, por su parte, entiende que el artículo 11.7 viola el principio constitucional de igualdad (art. 14) puesto que los candidatos presentados en listas de partidos se encontrarian en inferioridad de condiciones con respecto a los presentados en listas de independientes o a los que lo hubieran hecho como tales en listas de partidos.

62 Así en la sentencia 10/1983 de 21 de febrero se dice que lo propio de la representación es el establecimiento de la presunción de que la voluntad del representante es la voluntad de los representados, en razón de la cual son imputados a éstos en su conjunto, y no sólo a quienes votaron a su favor o formaron la mayoría los actos de aquél. (BOE, número 70, 23 de marzo de 1983. Suplemento pág. 9). También que cuna vez elegidos los representantes no lo son de quienes les votaron sino de todo el cuerpo electoral» (BOE de 23 de marzo de 1983, suplemento, pág. 10).

63 Esta formula de identidad democrática se admite en la Constitución de algunos Estados norte-americanos (recall).

64 KELSEN indica como una fórmula para intensificar los elementos democráticos del parlamentarismo, que el diputado pierda su mandato al separarse o ser expulsado del partido por el que fue designado. "Tales disposiciones resultan por consecuencia natural en los casos de sistema electoral por listas, pues en ellos los electores no designan al diputado por su persona, sino que su voto más bien significa un acto de adhesión a un partido determinado, de manera que el candidato obtiene su representación sólo en virtud de su filiación al partido del elector, siendo lógico que el diputado pierda su mandato tan pronto deje de pertenecer al partido que le ha enviado al Parlamento". (KELSEN, Esencia y valor de la democracia. Editorial Nacional. México, 1974). 
tivo que permiten las elecciones a representantes, en el entramado de partidos en el que se desarrolla la democracia actual. La imposibilidad de revocar el acta del representante que causó baja en el partido, pone al electorado que lo votó ante un concejal, que en ejercicio de su independencia, puede frustrar las-expectativas de acción política que lo llevaron al triunfo electoral.

En cualquier caso es engañoso razonar sobre este tema, sin contar con que la pieza que articula nuestra democracia de partidos es el mandato que aquéllos ejercen sobre sus representantes electos, lo que se sobrentiende por todos los que participan en la elección.

\section{B. LA PROBLEMÁTICA DE LAS CONSTITUYENTES. EL RECHAZO A LA DEMOCRACIA DE IDENTIDAD}

\section{LA POSICION DE LOS GRUPOS POLITICOS}

Como fuimos viendo, el debate en torno al texto consensuado de la ponencia constitucional, tanto en la Comisión de Asuntos Constitucionales como en los plenos, llevó a un progresivo acotamiento de todo lo que apareciera como democracia no representativa. Lo que, entre otras cosas, puso de manifiesto el carácter improvisado de la ponencia y el poder de convencimiento de uno de los ponentes en la misma, Fraga, único defensor del "consenso original" frente a la suspicacia a posteriori generalizada.

¿Qué intereses y qué argumentos políticos enmarcaron este proceso de progresiva restricción?

El Diario de Sesiones da cuenta de la prolija discusión en torno a los principios de referencia, cuyo análisis puede ser revelador, a pesar de las conocidas limitaciones de este pobre y teatral contexto, en el que, y en palabras de uno de sus actores, "la discusión sobre algunos puntos fundamentales quedó prácticamente escamoteada y, muy a menudo, los debates quedaron emasculados y reducidos a poco más que un simulacro" ${ }^{65}$. No obstante, el hecho de que las fuerzas políticas no presentaran de manera articulada ante la opinión pública sus directrices constitucionales, debido probablemente al peculiar afán negociador presente en todo el proceso de transición, nos obliga a usar como fuente los debates parlamentarios. 
Nos referiremos en pocas palabras a las posiciones de los principales grupos parlamentarios en torno a esta cuestión. Alianza Popular, representada por D. Manuel Fraga, defiende, como eje central la consideración de la Constitución como mixta de elementos de democracia representativa y democracia directa y semi-directa. La argumentación es la que sigue: Los Estados modernos sólo se pueden organizar sobre la base de la representativa, que es instrumento imprescindible para integrar grandes conjuntos políticos. La democracia no delegada, aún siendo hoy históricamente residual, cumple una función esencial como compensadora de la delegación política institucionalizada. Con ella se atenúa o evita el riesgo de caer en la "partitocracia", "que se produce en el momento en el cual los partidos no actúan como promotores de corrientes de opinión, de programas y candidatos, sino como monopolizadores del proceso político" ${ }^{66}$. Las técnicas de corrección que se proponen son: la iniciativa legislativa popular, el Concejo abierto, los diversos tipos de referendos, y la iniciativa popular en la reforma constitucional, entre otras cosas. Se trataría de asegurar la soberania del pueblo en su identidad frente a la del Parlamento, a través de la creación de vías de formación de la voluntad general en las que no intervinieron los partidos.

El grupo comunista parte de la necesidad, declarada explicitamente, de preservar la "Soberanía del Parlamento": las prácticas de democracia directa $u$ otras similares sólo pueden conducir a la interferencia del proceso legislativo ordinario y, concretamente, la iniciativa popular se presta a toda clase de demagogias y puede generar una extrema inseguridad jurídica. Para el diputado Solé Tura, el problema no es la partitocracia sino, al contrario, la imperiosa necesidad de que los partidos se fortalezcan y se conviertan en canales, cada vez más adecuados, de expresión de la voluntad popular; "que sean reconocidos como intérpretes de las grandes masas de la población" ${ }^{67}$. "En lo que la democracia no puede transigir es en la desaparición de los partidos y en el desarrollo por via sustitutoria, de formas pseudoparticipativas, como los referendos que muy a menudo se convierte en plebiscito" ${ }^{68}$. La compensación a la representación vendrá dada, en todo caso, por la vía de lo que se denomina "democracia de base", que consiste en el desarrollo de las formas de participación y organización popular, en la descentralización del poder político, $y$ en el fomento de las autonomías a todos los niveles ${ }^{69}$.

En el grupo parlamentario de UCD, Herrero de Miñón justifica la democracia representativa partiendo de la necesidad de organización del

\footnotetext{
66 Fraga Iribarne. "Diario de Sesiones". Pleno del Congreso. 13 de julio de 1978.

67 JoRd Sole TURA. "Diario de Sesiones". Comisión de Asuntos Constitucionales y Libertades Públicas. 6 de junio de 1978.

68 JORDI SOlE TURA. "Diario de Sesiones". Pleno del Congreso. 13 de julio de 1978.

69 SOLE TURA resume posteriormente, las razones que impulsaron a los constituyentes a dejar de lado gran parte de las fórmulas referendarias en el libro Parlamentarismo y Democracia, (publicado por la Fundación Pablo Iglesias, Madrid, 1981, págs. 96 y siguientes).
} 
pueblo: «El Estado democrático, es el Estado del pueblo y no el pueblo sin el Estado" (en frase de Ortega); "es el pueblo en el ágora y no en la calle» ${ }^{70}$. Representación y partidos políticos son la base de esta organización. No obstante, se declara la necesidad de compaginar el principio representativo con el de participación directa, aunque se contempla ésta con cautela, dada la fragilidad del sistema parlamentario. Vale más la pena asentar con nitidez este sistema evitando procedimientos que pudieran llevar a técnicas de veto plebiscitario, y que "podrian ser utilizadas por minorías extraparlamentarias" para introducir conflictos graves en el adecuado funcionamiento del sistema.

El grupo parlamentario socialista se muestra de acuerdo con las tesis de UCD: Se considera que la voluntad del pueblo se expresa a través del Parlamento y se mantiene una actitud recelosa frente a los sistemas de democracia no representativa, particularmente frente al referéndum, por la facilidad con que se simplifican y manipulan las preguntas, y por el peligro de dividir al país en dos bloques. En otro orden de cosas, este grupo se muestra como máximo defensor de la participación ciudadana en la administración de la justicia. Esta sí aparece como forma adecuada de participación directa, factible y necesaria en la medida en que en ella se da también una delegación, puesto que, constitucionalmente, el poder judicial emana del pueblo.

\section{CONSERVADURISMO Y DEFENSA DE LA DEMOCRACIA DE IDENTIDAD}

Para interpretar adecuadamente esta polémica hay que contar con que detrás de la discusión político-teórica sobre principios democráticos - y en cierta forma encubierta por ella- se estaba dando otra que afectaba a cuestiones más concretas, relacionadas con la aplicación práctica de uno u otro principio, y que enturbiaban la contradicción esencial. Nos sive de ejemplo, en este sentido, el referéndum de iniciativa autonómica, que fue fruto de una cesión concreta, enmarcada en la negociación global entre los representantes de los intereses del Estado y de los territorios autónomos.

¿Qué había del planteamiento de Alianza Popular, promotora del principio de identidad? Cabría pensar - como así lo manifestaron distintos grupos parlamentarios- que nos encontramos ante la clásica defensa, más o menos velada, de las formas plebiscitarias y aclamativas. Si esto no se

70 Herrero de Miñon. “Diario de Sesiones". Comisión de Asuntos Constitucionales y Libertades Públicas. 5 de mayo de 1978. 
dio de una manera consciente y total, lo cierto es que en el grupo popular se apreciaba una cierta preocupación por crear canales de legitimación plebiscitaria, que funcionaran como alternativa al sistema representativo.

Por un lado, lo exiguo de su representación parlamentaria en aquel entonces motivaba, lógicamente, la orientación hacia las fórmulas de decisión política extraparlamentaria. Por otro, la enorme influencia sobre los medios de comunicación que tenían los intereses sociales a los que representaba, era probablemente muy tenido en cuenta a la hora de pronunciarse por la consulta directa. También la presumida tendencia de las masas al conservadurismo que parece deducirse de la experiencia referendaria, era acogida por Fraga cuando insistía en la "sensatez del cuerpo electoral», frente a un previsible aventurismo «izquierdista" de los representantes ${ }^{71}$.

No parece extraño que en esa cerrada defensa de los procedimientos de la democracia de identidad, se contemplara la posible instrumentalización de aquéllos para frenar lo que de excesivamente progresista tuviera la legislación de la Cámara de representantes, imponiendo una especie de "veto plebiscitario»" 72 .

Algo que condicionó el apoyo de este grupo a las formas de identidad democrática era la necesidad de dar algún contenido a ese populismo con el que se quería revestir esta formación que compensara sus tesis antisocializantes. Nada mejor que una forma de entender la democracia distinta a la del liberalismo clásico en la que, además, se había pretendido legitimar el régimen anterior, del que procedian los políticos del grupo popular.

En cualquier caso, pretender que a través de los mecanismos de identidad democrática se materializa la "participación directa" de los ciudadanos sin mediaciones es, cuando menos, engañoso. Aparentemente se trata con ellos de eludir a los partidos y a la representación política por ellos controlada, pero hay que contar con que hoy constituyen instancias mediadoras además de los partidos, los órganos de la opinión pública, los medios de masas, etc..., y que aquéllos actúan sobre los medios de

71 Lo cierto es que aunque la democracia directa fue inicialmente una reivindicación de signo progresista acogida incluso por el pensamiento socialista, la primera puesta en práctica de la misma -en la Suiza de la segunda mitad del siglo pasado- puso de manifiesto el carácter más conservador del pueblo en relación con sus representantes. Hasta el punto de que los radicales suizos que lo habian introducido en aquel país lo rechazaron, y los conservadores franceses defendieron en la misma época el referéndum legislativo para frenar la legislación laica. En cualquier caso, el populismo conservador siempre puede contar con el poder de la inercia ideologica de las culturas anteriores sobre las masas. Esto se corresponde con el inicial y necesario carácter minoritario de las fuerzas progresistas, lo que explica su oposición a las consultas populares.

72 Jordi Solé Tura. «Diario de Sesiones». Pleno del Congreso. 13 de julio de 1978. La especial insistencia en mantener el referéndum sobre leyes aprobadas por las Cortes pero aún no sanciondas es buena prueba de ello. 
comunicación. La manipulación de la opinión pública y del comportamiento electoral harían su aparición en cualquier consulta directa, siendo en ello, además, agentes destacados los partidos ${ }^{73}$.

El tema del Jurado puso en evidencia el carácter instrumental de lo que aparecian como cerradas defensas de principios teórico políticos de carácter general, especialmente en el caso de Alianza Popular y en apariencia tan favorable al de identidad. Para esta formación, la genérica participación de los ciudadanos en la Justicia puede llevar a los tribunales mixtos, lo que supone «la constitucionalización de algo parecido a los tribunales populares» ${ }^{74}$. Contrariamente, la «participación democrática» en la Administración de Justicia es, para el PSOE, una manifestación de la soberanía popular. Quizás no estén absolutamente claras las razones por las que Alianza Popular y UCD quieren confiar la Justicia a la uprofesionalidad, independencia y seguridad de Jueces y Magistrados" 750 las del PSOE en buscar la participación del pueblo (en forma de jurados, tribunales mixtos, elección de la judicatura, etc.), pero sí el hecho de que de esta participación se deduciría una disminución del control que, sobre una parcela del Estado, tenían sectores conservadores.

Es decir, que la inversión observada en torno a este tema no es más que un giro táctico en la lucha por obtener posiciones favorables dentro del aparato del Estado. Alianza Popular, constituida en tribuna del corporativismo judicial, estaba muy interesada en evitar cambios perturbadores en el mundo, supuestamente conservador, de la judicatura.

\section{EL CONSENSO Y LA OPCION DE LOS CONSTITUYENTES POR UNA DEMOCRACIA ESTRICTAMENTE REPRESENTATIVA}

Como vimos, y con matizaciones no excesivamente relevantes, coincidieron PSOE, UCD y PCE frente a la posición contraria de Alianza Popular, teórica e incansable defensora de la democracia no delegada. La izquierda española con ellos, abandonó esa añoranza rousseauniana,

73 Habermas ha destacado la transformación de los partidos, inicialmente instrumentos para delegar la voluntad popular y posteriormente agentes "formadores de la misma", especialmente con la aparición del "partido de integración". "Como alternativa al partido de clase surgió el modelo - casi siempre poco claramente distinguible del partido de clase - del partido de integración; captaba temporalmente a los electores y los motivaba a la aclamación sin remover su minoría de edad política. En él es decisivo quien disponga del medio de coacción o convencimiento necesario para influir representativa o manipulatoriamente sobre el comportamiento electoral de la población". (HaBERmas. Historia y crítica de la opinión pública, ob. cit., pág. 230).

74 De La Fuente. “Diario de Sesiones". Pleno del Congreso. 13 de julio de 1978.

75 DE LA FUENTE. “Diario de Sesiones". Comisión de Asuntos Constitucionales y Libertades Públicas. 8 de junio de 1978. 
que si bien no expresamente formulada en programas políticos, si se incluía tradicionalmente en sus perspectivas de transformación política. La defensa de la "soberanía del Parlamento", a la que literalmente aludía uno de los diputados, quedó justificada, por otro lado, ante la actitud opuesta del grupo popular, cuyos miembros y cuyas propuestas políticas carecían de "credibilidad democrática".

Como se ha señalado, un hecho concreto, los referendos italianos del 11 de junio de 1978, en pleno debate constituyente, influyeron negativamente en la actitud de los partidos ante las instituciones de la democracia semidirecta $^{76}$.

Pero es el proceso de gestión de nuestra democracia, teñido por un especial predominio de los partidos en el sistema político, lo que condicionó más claramente la opción de los constituyentes. Como ha escrito RUBIO LLORENTE, en la transición española, «aunque el titular teórico del poder constituyente es el pueblo español, los actores ${ }^{77}$ reales del proceso constituyente son los partidos", lo que en absoluto debe sorprender en el marco de la democracia post-industrial.

Nuestro sistema político, con sus dilatadas lagunas democráticas, no ha sido ajeno a la transformación sufrida en todos los Estados democráticos. Producida, primero, por el hecho de que los partidos políticos se han apoderado literalmente del sistema, sobre todo en lo que hace a los mecanismos representativos; segundo, por el aumento de la influencia en las organizaciones politicas de sus élites burocráticas. La consecuencia ha sido que la decisión política, en buena medida, se ha desplazado al ámbito de las restringidas minorías de políticos que dominan el aparato organizativo de sus respectivos partidos. Este proceso tan reiteradamente descrito, tuvo aquí una expresión radical, al término de un largo período de prohibición de toda asociación política, del que surgieron los partidos en forma de estrechas formaciones de luchadores antifranquistas, necesariamente imbuidos del subterfugio del "centralismo democrático"; o en forma de improvisadas y apriorísticas reuniones de cuadros dispuestos a organizar una futura opción política. Ningún partido al comienzo de la transición podía atribuirse una implantación extensiva en algún sector social, ni mucho menos, mostrarse como una auténtica organización de masas.

Esta estructura interna de nuestros recién permitidos partidos, en los que la única relación observable entre base y dirigente era la aceptación, casi siempre mecánica, por parte de aquélla de la política de éste, y

76 Especialmente los resultados del referéndum relativo a la Ley de Financiación de los Partidos confirmaron las aprensiones de éstos frente a los mecanismos de democracia directa (el 43 por 100 de los votantes se pronunciaron a favor de su derogación). CRUz VILLALON, ob. cit., págs. 151 y siguiente.

77 Rubio Llorente, La Constitución española de 1978. Libro homenaje a Garcia Pelayo. Universidad Central de Venezuela. Caracas, 1980. 
la composición misma de los grupos parlamentarios formados en aquel período, en los que sobresalían unos pocos líderes, favorecieron la formación de una élite política muy independiente en la toma de sus decisiones. Hasta el punto de hacer muy explicito un moderno sesgo ideológico de la representación política: la pretensión de la presencia popular en el Parlamento, dominado por las élites partidarias.

En nuestro proceso constituyente el protagonismo de los partidos restó importancia al Parlamento como lugar de discusión pública, de acuerdo con la tendencia generalizada en los sistemas democráticos que suceden al Estado de Derecho Liberal. La propia decisión constituyente le fue sustraída: ésta se tomó en el ámbito de la negociación entre los partidos y otras fuerzas sociales, excluyendo la publicidad, es decir, la consustancial presencia del pueblo sin la que la representación política queda desvirtuada.

La tan descrita fórmula consensual para la elaboración del texto constitucional del 78 , se tradujo esencialmente en la negociación no pública con destacada incidencia electoral. Los trabajos de la ponencia constitucional ${ }^{78}$ en los que se dio a luz al primer texto consensuado, no se hicieron públicos. Los debates en torno al mismo, primero en la Asamblea de Asuntos Constitucionales y en el Pleno del Congreso, y más tarde en el Senado (Comisión y Pleno), en gran parte no fueron más que una formalidad que concluía en la ratificación de acuerdos concertados fuera de las Cámaras. Las discrepancias no se explicitaron, el disenso real quedó al margen de la transcripción publicitada en el Diario de Sesiones.

El consenso como método constituyente se explica, si se tiene en cuenta que la negociación informal entre las fuerzas políticas protagonizó la política de la transición, como derivación necesaria de la resolución de la antinomia reforma-ruptura, a favor de la segunda, sobre todo a partir de la aceptación por la oposición democrática de la Ley de Reforma Política.

Si el compromiso, como indica WEBER, es el medio específico para la formación de la voluntad estatal y en el que descansa, inevitablemente, en todo Estado de masas, la mayoría de las leyes ${ }^{79}$, en el momento politico de la transición se hizo absolutamente imprescindible.

Obviamente, la naturaleza de nuestro consenso no era el acuerdo racional libre, puesto que en cuestiones fundamentales los intereses sociales cierran el acceso a la comprensión mutua, supuesto previo del

78 Elegida en la Comisión de Asuntos Constitucionales del Congreso, estaba compuesta por siete miembros, tres de la Unión de Centro Democrático, uno del Partido Socialista Obrero Español, uno del Partido Comunista, uno de Alianza Popular y un representante de las minorias catalana y vasca.

79 Max Weber. Economía y Sociedad. Fondo de Cultura Económica, pág. 1112. 
consenso entendido en su sentido genuino. Nuestro compromiso constituyente más que con un acuerdo racionalizante, tenía que ver con una transación, en la que la eventual cesión en los presupuestos e intereses de cada posición político-social, personificada por los líderes de los partidos que actuaban como partes, hacía adecuada la exclusión de la publicidad.

En la transición española, este tipo de compromiso tuvo una dificultad añadida a los conflictos propios del Estado social: la presencia amenazante en el aparato del Estado de enclaves poderosos del régimen anterior. Esto tuvo un efecto no despreciable en la ampliación e intensificación del mecanismo consensual. Ante la crisis endémica a la que les sometían los "poderes fácticos" y para reforzar y prestigiar a la naciente democracia, las fuerzas políticas de oposición renunciaron al conflicto y a la movilización de masas y se orientaron hacia la convergencia, que se puso en manos de la negociación entre sus líderes. En realidad, la concertación se amplió a esas fuerzas antidemocráticas que, aunque ausentes de la negociación, y a pesar del disenso radical que practicaban, fueron, de alguna forma, parte en el convenio, pues, primero, potenciaron la fórmula del compromiso entre sus enemigos, $y$, segundo, acentuaron la moderación conservadora del contenido del mismo.

A la postre, y en lo que respecta al texto constitucional y ante las dificultades extremas de la transición política que se realizaba,

«El método consensual significó entre nosotros en la práctica la elusión de todas aquellas decisiones que resultaron absolutamente inaceptables para los protagonistas del proceso constituyente, prescindiendo en consecuencia de lo que se hubiera podido imponerse sólo merced a la fuerza de los votos» ${ }^{80}$.

En lo que no era negociable, se hizo uso inmoderado de la delegación en el legislador futuro: la remisión ad calendas graecas (en frase de Fraga Iribarne) de decisiones constitucionales tuvo, indudablemente, una intención restrictiva de la publicidad, pues la categoria de la norma es indicativa de su mayor o menor relevancia pública.

Otra forma de eludir consensuadamente la decisión constitucional fue el uso del compromiso apócrifo consistente en "una fórmula que satisfaga todas las exigencias contradictorias y deje indecisa, en una expresión anfibológica, la cuestión litigiosa misma» ${ }^{81}$.

80 RuBio LloRente, La Constitución del 78, ya citada.

81 CARL SCHMITT. Teoría de la Constitución, pág. 36. Ante la imposibilidad de convenio -escribe Del Aguila - la solución que se aplicó fue la siguiente: "dar con fórmulas lo suficientemente ambiguas que pudieran ser interpretadas de formas diversas $y$, aunque dieran paso de hecho a la interpretación desde el poder, satisfacieran a la vez todas las exigencias, por contradictorias que fueran, dejando aparentemente en el aire la solución con- 
En fin, el contexto - someramente descrito- en el que se dio la opción constitucional explica, por lo menos parcialmente, el sentido de la misma. El entramado político de las constituyentes, con un sistema de partidos necesariamente jerarquizados; en el que se da una preocupación por el engarce sin rupturas entre el antiguo y el nuevo régimen, y en el que la toma de decisiones tenía lugar a través del uso del consenso y la negociación extraparlamentaria no pública, condicionó en sí mismo la adopción radical del principio representativo.

La democracia representativa hace posible la negociación en el marco del pluralismo, para atenuar, y en su caso, integrar el conflicto. La aplicación del principio de identidad necesariamente restaría la flexibilidad de la que el sistema democrático precisa para su reproducción. Esto debió aparecer con particular evidencia ante unos constituyentes empeñados en los equilibrios de un proceso de transición a la democracia como aquél.

Por otro lado, la asunción de la reforma negociada por la izquierda democrática, dio una especial relevancia al protagonismo de sus líderes parlamentarios. Pero en ese sentido, también a la representación en si misma, como vía de la acción política por encima de la movilización de masas, tan característica de la lucha antifranquista.

La distancia que el consenso generó entre el público y la clase política, extremando la autonomía de los representantes con respecto a aquél, fue rentabilizada por la exigua élite, que consensualmente adoptó la decisión constitucional que más favoreciera a aquella situación.

Sin duda, el acuerdo en torno al carácter de nuestra democracia, articulada casi exclusivamente en torno a la representación, tuvo que ver con un hecho que en nuestra consensuada transición se precipitó: la aparición de un interés específico y común en las élites parlamentarias, que sería el de admitir las mínimas influencias exteriores en su labor, el de ver los "verdaderos y emancipados intérpretes de las masas" 82 , sobre la base de una adecuada democracia representativa. No extraña, por ello, que en este aspecto se diera una benevolentium concertatio, y un acuerdo sobre la cosa misma, entre los dirigentes de organizaciones politicas tales como la UCD, el PSOE y el PCE, que, sin embargo, son representativas de las posiciones sociales que delimitan el conflicto sustancial en nuestra sociedad.

creta". ("La transición a la democracia en España, reforma, ruptura y consenso", en REP n. ${ }^{\circ} 25$, nueva época, pág. 121).

82 Jordi SOlÉ TURA. «Diario de Sesiones». Pleno del Congreso. 13 de julio de 1978. 